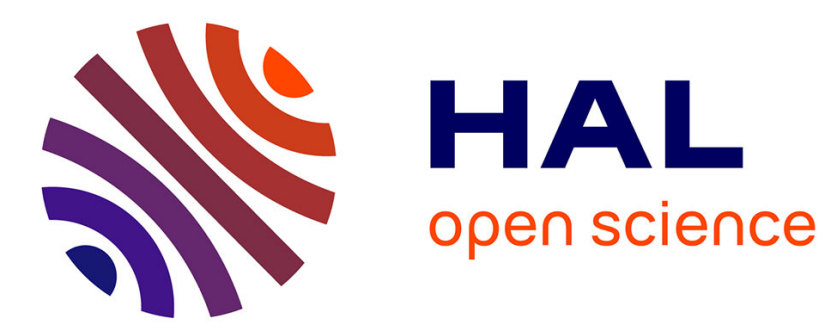

\title{
Courrier des lecteurs
}

- [.]revue Forestière Française, Rédaction

\section{- To cite this version:}

- [.]revue Forestière Française, Rédaction. Courrier des lecteurs. 1950, pp.187. 10.4267/2042/27668 . hal-03536012

\section{HAL Id: hal-03536012 \\ https://hal.science/hal-03536012}

Submitted on 19 Jan 2022

HAL is a multi-disciplinary open access archive for the deposit and dissemination of scientific research documents, whether they are published or not. The documents may come from teaching and research institutions in France or abroad, or from public or private research centers.
L'archive ouverte pluridisciplinaire HAL, est destinée au dépôt et à la diffusion de documents scientifiques de niveau recherche, publiés ou non, émanant des établissements d'enseignement et de recherche français ou étrangers, des laboratoires publics ou privés. 
fle \& « foehn » du nord, qui tient souvent de la « bora 》. L'état hygrométrique, qui n'est alors plus que de $30 \%$, s'oppose au maintien du Hêtre dans la Bregaglia, la vallée de Malenco, celle de Poschiava et la Valteline à l'est de Tirano.

Das.Abbrennen von Hiebsflächen in Finnland, par VeStERINEN, p. $5 \mathrm{I}-54$.

La culture des céréales a été autrefois intercalée entre des cultures forestières suivant le mode du sartage. Des surfaces considérables, en forêts maintenant, ont été autrefois soumises au feu et, à l'heure actuelle, on procède encore souvent à l'incinération avant de semer. L'opération donne d'ailleurs de bons résultats quand elle est bien conduite. Il ne faut pas perdre de vue cependant que « si le feu est un bon serviteur, c'est un mauvais maitre.

L. SChAEFFER.

\section{COURRIER DES LECTEURS}

\section{LA MALADIE DU ROND}

Dr X. à M... - Je serais heureux d'avoir votre avis sur les causes de dépérissement d'épicéas de 20, 30, 40 et même 50 ans que je possède dans le Puy-de-Dôme. Des arbres de belle venue jusqu'ici se mettent à dépérir sur des surfaces de quelques dizaines de mètres carrés. Finalement les vents d'automne ou la neige amènent la chute de l'arbre et on constate qu'une ou plusieurs racines principales sont pourries. Ou bien, si on coupe l'arbre avant sa chute, on trouve dans le pied une cavité qui remonte plus ou moins haut 'dans le fût, ce qui enlève une grosse valeur marchande à l'arbre.

Réponse. - La présence d'une pourriture du tronc et des racines prouve qu'il s'agit d'une maladie parasitaire. Il doit s'agir de la pourriture rouge du cœur causée par Ungulina annosa.. En général, la vitalité apparente de l'arbre n'en est que peu affectée, mais, au cas particulier, il est probable que ces épicéas déjà fortemen: atteints par la maladie ont été achevés par la sécheresse particulièrement accentuée qui a sévi l'été dernier.

En raison de la manière dont elle se propage, la maladie a reçu le nom de " maladie du rond ». Elle est en particulier décrite sous ce nom dans le bulletin $\mathrm{n}^{\circ} 6$ de la Commission d'études des ennemis des arbres. 